\title{
ECC
}

\section{The synthesis of silver nanoparticles using Beetroot extract and its antibacterial and catalytic activity}

\author{
Sima Mehdizadeh, Nahid Ghasemi*, Majid Ramezani \\ Department of Chemistry, Arak Branch, Islamic Azad University, Arak, Iran
}

Received: 18 May 2019, Accepted: 12 June 2019, Published: 1 November 2019

\begin{abstract}
Silver nanoparticles (NPs) have been synthesized by aqueous Beetroot extract. Effective parameters on the synthesis of silver NPs like $\mathrm{pH}$, extract volume, silver nitrate concentration and time of reaction have been investigated at room temperature. The synthesized silver NPs have been studied with different analysis like UV-Vis, FT-IR, FE-SEM, TEM, and XRD. Our analysis indicates that the level of Surface Plasmon is $439 \mathrm{~nm}$. The shape of NPs is spherical and the size is 20-30 nm using FESEM and TEM technique. Four bacteria (Escherichia coli, Staphylococcus aureus, Bacillus subtilis and Salmonella typhymurium) were used as references bacteria to analyze the antibacterial effect. Antibacterial results show that gram negative bacteria are so sensitive to synthesize silver NP. The recommended method was completely eco-friendly.
\end{abstract}

Keywords: Beetroot; nanoparticles; antibacterial activity; catalytic activity.

\section{Introduction}

Nowadays, nanotechnology is recognized as an attractive and important field of modern research. It is involved in preparation of NPs with different sizes, from 1 to $100 \mathrm{~nm}$. NPs have wide ranges of application in numerous areas such as: chemical industries, electrical industries, biomedical science, space industries, drug delivery, cosmetic industries, catalytic areas and other fields [1,2]. The synthesized NPs can illustrate physical, chemical and biological methods. The physical and chemical methods were introduced to reduce metallic ions to NPs respectively, although chemical methods have some certain drawbacks such as, using chemical toxins and producing some hazardous compounds in their products [3-8]. The close relation is seen between synthesis of biological particles and biogenesis, the main significance is referred to biological approaches and simplicity in synthesizing NPs, as well as, time of reaction is less than other methods. Some factors such as, low toxicity and cost, high yield and biocompatibility are so crucial and important. Additionally, the size of the synthesized NPs can be easily controlled by the use of various parameters like $\mathrm{pH}$ and temperature and concentration [9]. Gordea-Torresdey and et al, reported the synthesis of silver and gold NPs using lucerne plant (Particles size were between 20 and 40 $\mathrm{nm}) \quad[10,11]$. Silver NPs were synthesized using different plants [12-

*Corresponding author: Nahid Ghasemi

Tel: +98 (86) 34135421, Fax: +98 (86) 34135421

E-mail: n-ghasemi@iau-arak.ac.ir, anahid3@gmail.com 
14], i.e. in 2009, Yong Song and colleagues used five extracts of Pine, Persimmon, Magnolia, Platanus and Ginkgo plants for synthetizing the silver NPs (The average particle size was from 10 to $500 \mathrm{~nm}$ ) [15]. Similar works have been done in 2012 and 2016 using extract of Ananas comosus (12 nm) and Apple $(30 \mathrm{~nm})$, respectively $[16,17]$. Bonnnia and co-workers synthesized silver nanoparticles applying Polygonum hydropiper (45 to $70 \mathrm{~nm}$ ) and studied catalytic degradation of Methylene Blue [18]. Jayanta and coworkers synthesized silver NPs by the use of green method and surveyed the reduction process of methylene blue ( 8 to $32 \mathrm{~nm}$ ) [19]. Ajitha and co-workers synthesized silver NPs using Phyllanthus amarus leaf extract (30 to $42 \mathrm{~nm}$ ) and analyzed its antimicrobial and catalytic activity [20]. Godfrey and co-workers synthesized silver NPs using Asytasia gengetica leaf extract (40 to 60 $\mathrm{nm})$ and surveyed its antibacterial effects [21].

In this study, we synthesized silver NPs applying the extract of Beetroot (BR). Beetroot as a vitamin-rich vegetable is easily available and consists mainly of beneficial compounds such as, Manganese, Folate, and Magnesium [22]. Accordingly, we have selected it as a reduction agent for this synthesis (Figure 1). Some pigments in the Beetroot are soluble in water; the pigments are influenced by different factors like moisture, $\mathrm{pH}$, temperature, light and oxygen. The pigments have antiviral and antibacterial activities, such as preventing the growth of cancer cells. The pigments are used in different ways for making and enriching colors of foodstuff that was approved by European Union as E-162 [22]. The antioxidant activity in pigments is used to prevent releasing free radicals, therefore, some strict illnesses such as cancer and cardiovascular diseases will be restricted by pigments [23]. Nowadays, noticeable improvement in different fields like manufacturing and using new materials and methods of nanotechnology is obvious and clear. In the recent years, metal NPs have been used in the wide ranges of new technologies. Some interesting features in metal nanoparticles such as Surface Plasmon Resonance (SPR), optical features, suitable catalytic function, antibacterial and antifungal activities and other significant features transforms, it demonstrates as a significant tool in different industrial.

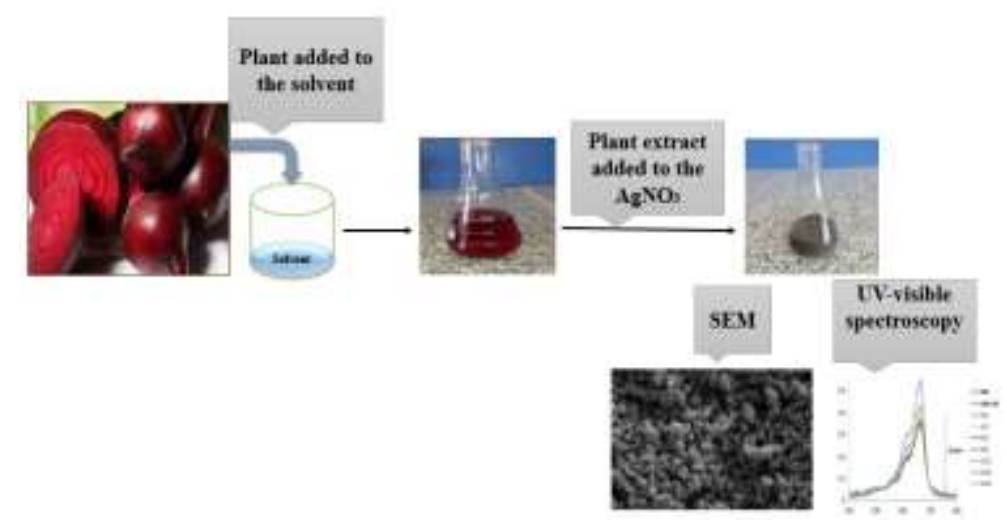

Figure 1. Preparation of silver NPs by Beetroot Extract 


\section{Experimental}

\section{Materials}

The samples (Beetroot) were collected by local markets (Arak, Iran) and, also, chemicals were prepared from the Merck company (Germany). The primary technique that was used in the characterization of metallic NPs was UV-Vis spectroscopy [24]. The UV-Vis spectrum of dispersed nanoparticles (AgNPs) was measured using the UVVis spectrophotometer (300 to $800 \mathrm{~nm}$ ) (UV-Vis Agilent 8541). Fourier Transform Spectroscopy (FT-IR) has been applied to identify the potential of functional group that was presented in the Beetroot extract and was responsible for the reduction of the silver ions. FTIR studies were carried out by the use of Perkinelmer Spectrum two spectrophotometer. The achieved samples were prepared using $\mathrm{KBr}$ pellet technique. The XRD diffraction is used widely to establish the metallic nature of particles. The crystalline structure of the silver nanoparticles was recognized by applying Philips company $\chi$ ' pert Pro Xray diffract meter by monochromatic $\mathrm{Cu}$ $\mathrm{kx}$ radiation $(\lambda=1.54 \AA)$ that were maintained at $40 \mathrm{kV}, 30 \mathrm{~mA}$. Field emission scanning electron microscopy (FESEM) (VEGAS-TESAH Model) was practically used to characterize the size, shape and structure of nanoparticle. Transmission electron microscopy (TEM) by Philips Company (CM120) was applied for doing further studies.

\section{Preparation of the Beetroot extract}

The Beetroots were washed and cleaned with drinking water to remove any pollution. In the next step, the Beetroot was cut into small pieces and dried at room temperature. Finally, the dried Beetroot was powdered using grinder mixer. 10 gr of Beetroot powder was added into $100 \mathrm{~mL}$ of distilled water and allowed to boil, after that, it remained for $5 \mathrm{~min}$ and was filtered with the whatman No.1 paper. The extract of plant was centrifuged at 4000 $\mathrm{rpm}$ and stored in refrigerator at $4{ }^{\circ} \mathrm{C}$ for the studies.

The synthesis of silver NPS

$100 \mathrm{~mL}$ of silver nitrate $\left(\mathrm{AgNO}_{3}\right) 10$ $\mathrm{mM}(1.7 \mathrm{~g})$, was prepared as a stock solution and used for preparing diluted concentration $(1,1.5,2,2.5,3$ and 5 $\mathrm{mM})$. By adding the Beetroot to these solutions, the color of solution started to change from ruby red to brown, due to reaction of $\mathrm{Ag}$ ions and formation of $\mathrm{Ag}$ NPs, Figure 1 shows the formation of nanoparticles as well.

\section{Procedures}

The most important step for developing a synthesized principle is related to the optimization of variables. It has been proven that NPs size significantly depends on numerous factors, like concentration of Beetroot extract, salt solution concentration, $\mathrm{pH}$, and time. In order to obtain optimum conditions, 0.5 $\mathrm{mL}$ of extract with $5 \mathrm{~mL}$ of $\mathrm{AgNO}_{3}$ $1 \mathrm{mM}$ (169. $87 \mathrm{mg}$ ) was prepared and shaken for $30 \mathrm{~min}$ in variable $\mathrm{pH}(2,4$, $5,6,7,8$ and 10 ) for adjusting $\mathrm{pH}, \mathrm{HCl}$ and $\mathrm{NaOH} 0.1 \mathrm{M}$. In addition, the $\mathrm{pH}$ was measured with an EDT GP 353 ATC $\mathrm{pH}$ meter. In the next step, it was centrifuged (30 min) at $4000 \mathrm{rpm}$. The mentioned steps were applied and done for the extract volume $(0.1,0.2,0.25$, $0.5,1.5$ and $2 \mathrm{~mL}$ ), salt concentration $(1,1.5,2,2.5,3$ and $5 \mathrm{mM})$ and time variation $(10,20,40,60,90$ and 120 min) as well. After determining the optimal conditions for all of the parameters, the silver nanoparticles were resynthesized. The sediment was dried in an oven at $25^{\circ} \mathrm{C}$ after centrifugation and separation from extract. For characterization of the dried particles, UV-Vis, FT-IR, XRD, FESEM and TEM techniques were used. 
Catalytic activity of synthesized silver NPs

The kinetics of catalytic conversion of Methylene Blue (MB) using $\mathrm{NaBH}_{4}$ is followed by the use of the UV-Vis spectroscopy. The reduction of MB by helping $\mathrm{NaBH}_{4}$ in the presence of AgNPs was surveyed. It showed that the improvement of reduction was efficient. First of all, 0.008 gr of nanoparticle was reached $25 \mathrm{~mL}$ and solved by ultrasonic method, completely. The absorption of $1 \mathrm{~mL}$ of extract with $0.1 \mathrm{~mL}$ of $\mathrm{NaBH}_{4} 0.01 \mathrm{M}$ and $3 \mathrm{~mL}$ Methylene Blue 5-10 $\mathrm{M}$ was analyzed and measured at different times. The removal of $\mathrm{MB}$ by $\mathrm{NaBH}_{4}$ in presence of the AgNPs was monitored using the UV spectrum in $664 \mathrm{~nm}$.

Antibacterial activity of synthesized silver NPs

Escherichia coli (ATCC 25922), Staphylococcus aureus (ATCC 25923), Bacillus subtilis (ATCC 6633) and Salmonella typhimurium (ATCC 19430) were used as reference strains for antimicrobial assay.

Antibacterial assay by using disc diffusion method

In this method, antimicrobial activity was analyzed using paper discs. In the first stage, dilution of 0.5 Mac Farland was prepared for every reference strain,
Nutrient Agar was used as a suitable media culture for measuring antimicrobial activity. $500 \mu \mathrm{l}$ of each reference strain was separately used to culture on each Nutrient Agar plate as spread culture. Then, $20 \mu 1,30 \mu 1$ and 40 $\mu \mathrm{l}$ of each prepared sample (silver NPs by Beetroot extract) were used to saturate every paper disc, individually. (This step was done with three different volumes to find the Minimum Inhibitory Concentration (MIC)). The saturated discs with prepared sample (Silver NPs by Beetroot extract) were placed on the surface of agar, that reference microorganism was cultured on it previously. The plates were incubated at $37^{\circ} \mathrm{C}$ for $72 \mathrm{~h}$. Finally, the diameter of each inhibition zone was calculated precisely (saturated paper discs with distilled water was used as negative control for every test).

\section{Results and discussion}

Effect of $p H$ on silver NPs synthesis Investigation for the formation of $\mathrm{Ag}$ NPs was monitored by the UV-Vis spectral analysis. As a general rule, the characteristic part of surface Plasmon resonance (SPR) bond of silver NPs falls in the range of $300-800 \mathrm{~nm}$. The prepared NPs showed the SPR bond at 439 nm (Figure 2).

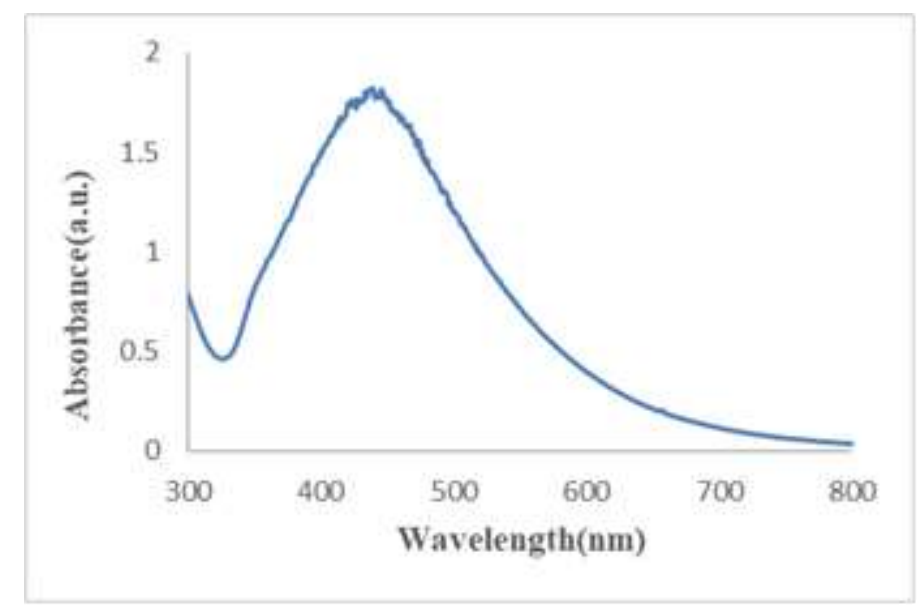

Figure 2. UV-Vis spectrum analysis of synthesized silver NPs 
It is evident that, the maximum value of wave length-absorbance was approved with the SPR of metallic silver in visible region, and, it confirmed the structure of the silver NPs. In order to gain optimum conditions, $0.5 \mathrm{~mL}$ of extract with $5 \mathrm{~mL} \mathrm{AgNO}_{3} 1 \mathrm{mM}$, in $\mathrm{pH}$ variations $(2,4,5,6,7,8$ and 10$)$ were mixed and, then, the samples were shaken for $30 \mathrm{~min}$, centrifuged at 4000 $\mathrm{rpm}$ for $30 \mathrm{~min}$, finally the UV spectrums were recorded. The effect of $\mathrm{pH}$ is shown in Figure 3.

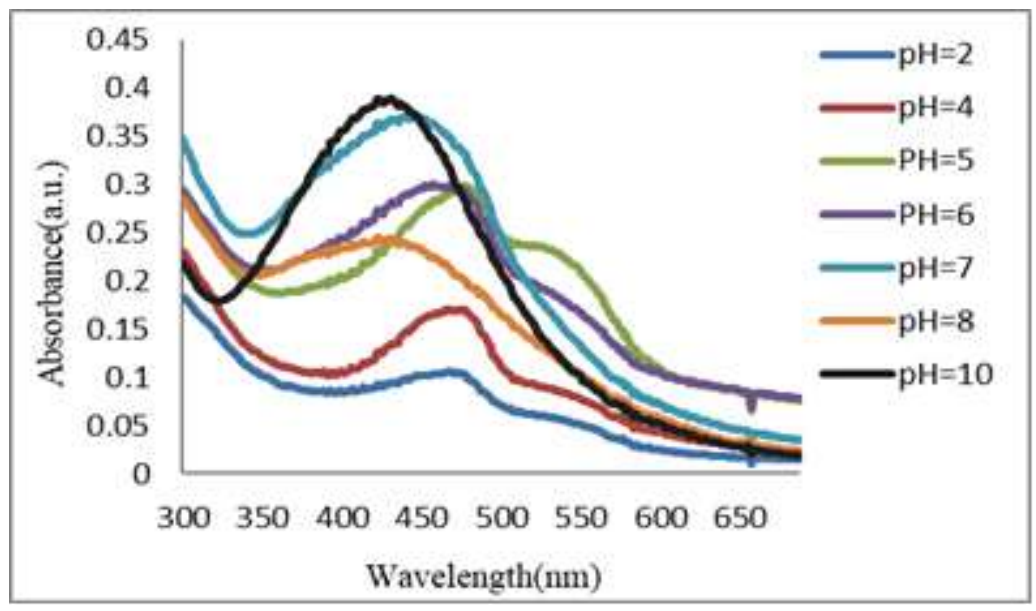

Figure 3. Effect of pH on silver NPs synthesis

Effect of extract volume of Beetroot on silver NPs synthesis

In order to find the best synthesis condition of silver NPs by Beetroot extract, $5 \mathrm{~mL}$ of $\mathrm{AgNO}_{3} 1 \mathrm{mM}$ was added into (0.1, 0.2, 0.25, 0.5, 1.5 and 2) $\mathrm{mL}$ of Beetroot extract, separately.
Then, $\mathrm{pH}$ of all samples was adjusted to optimized $\mathrm{pH}$. The samples were shaken for about $30 \mathrm{~min}$ and centrifuged at $4000 \mathrm{rpm}$ for $30 \mathrm{~min}$ at room temperature. The effect of extract volume is shown in Figure 4.

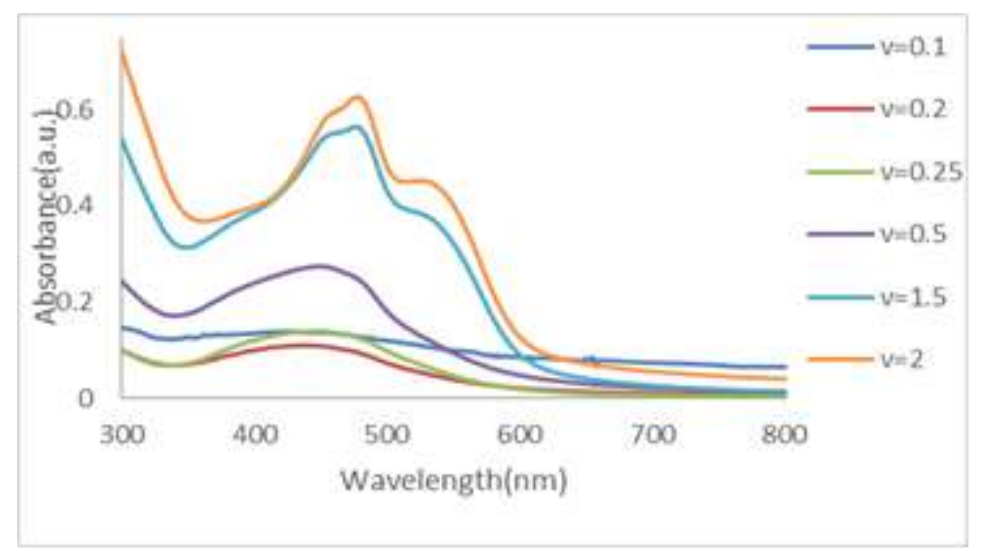

Figure 4. Effect of extract volume on silver NPs synthesis

Effect of salt concentration on silver NPs synthesis

The same attempts were applied in different salt concentrations $(1,1.5,2$, 2.5, 3 and $5 \mathrm{mM}$ ). The $\mathrm{pH}$ and extract volume were adjusted at optimized value, then, the UV spectrum was recorded. The effect of salt concentration is shown in Figure 5. 


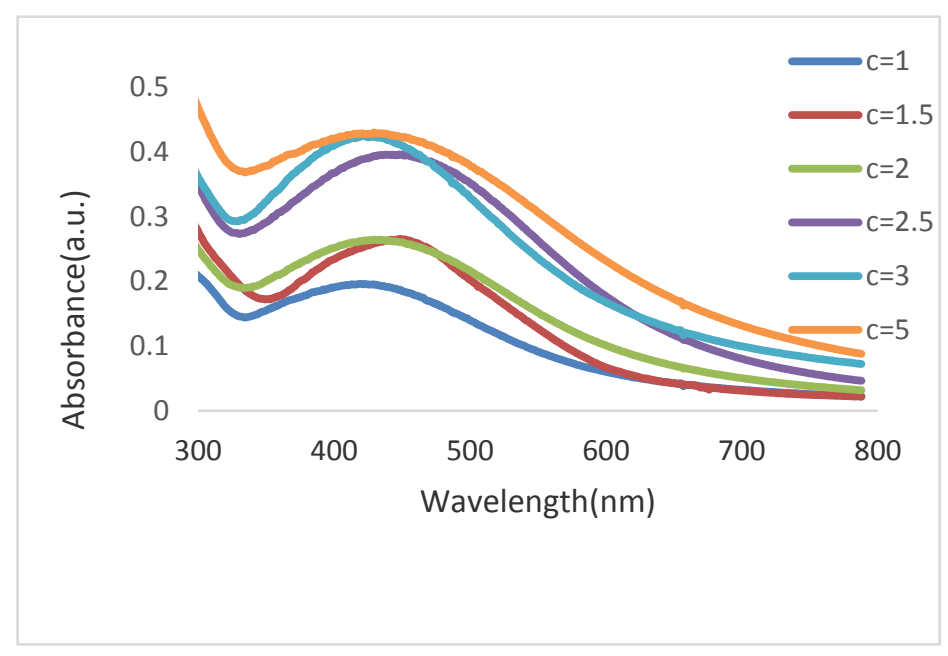

Figure 5. Effect of salt concentration on silver NPs synthesis

Effect of reaction time on silver NPS synthesis

In various times (10 to $120 \mathrm{~min}$ ) and optimum conditions, the UV spectrums were individually measured with increasing the time of interaction between reactors from $10 \mathrm{~min}$ (after bending reactors) to $60 \mathrm{~min}$, the value of absorbance increased tangibly. The effect of reaction time is shown in Figure 6.

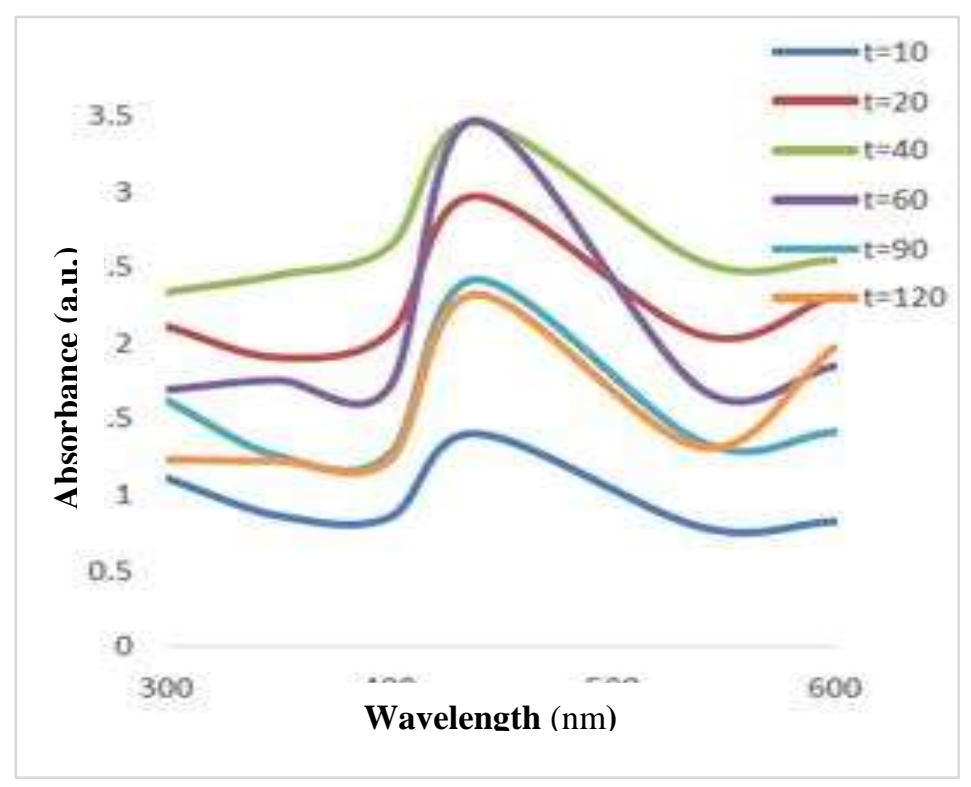

Figure 6. Effect of reaction time on silver NPs synthesis

The characterization Beetroot extract and silver NPs

Figure 7 depicts FT-IR spectra for the Beetroot extract and synthetized silver NPs by beetroot aqueous extract. The spectrum for silver NPs at the optimized conditions showed a sharp peak at 3412 $\mathrm{cm}^{-1}$ due to $\mathrm{OH}$ stretching vibration, and the peak at $2926 \mathrm{~cm}^{-1}$ that can be assigned to $\mathrm{C}-\mathrm{H}$ stretching vibration of alkanes. The absorption bond at 1634 $\mathrm{cm}^{-1}$ can be assigned to the carbonyl stretching vibration in amide bond. The $1384 \mathrm{~cm}^{-1}$ is attributed to the $\mathrm{C}-\mathrm{N}$ 
stretching or the $\mathrm{OH}$ bonding vibration. A peak at $1051 \mathrm{~cm}^{-1}$ in spectrum corresponds to the $\mathrm{C}-\mathrm{OH}$ vibration $[20$, 25-27]. The existence of functional groups is so clear and obvious through comprising spectrums of the extract FTIR and Ag NPs, it shows that, functional groups in extract have significant role for the reduction of silver ions and the stability of the formed NPs (Figure 7).
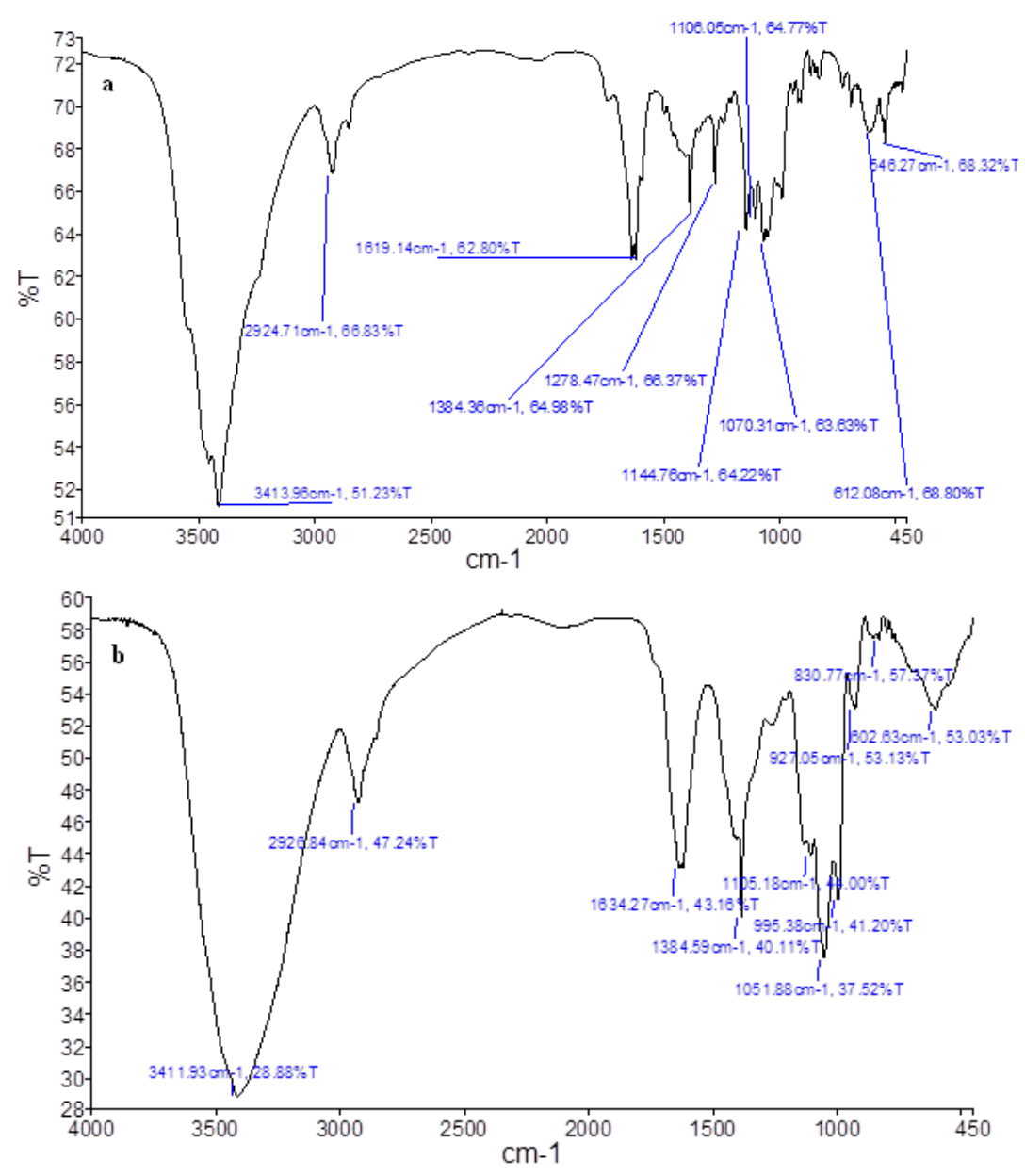

Figure 7. FT-IR spectra a) Beetroot extract, b) silver NPs using Beetroot extract in the optimum conditions

The XRD is used to establish the metallic nature of particles. The formation of synthetized NPs was supported by X-ray diffraction (XRD) measurements, Figure 8 . The XRD peaks can be indexed to (111), (200), (220) and (311) which reflect the cubic structure of AgNPs. The corresponding peak of (111) is more intense than the other planes and suggests that (111) is the predominant orientation as the synthesized AgNPs are crystalline in nature. The mean size of the AgNPs was gained using the Debye-Scherret's equation through determining the width of the (111). The strangest peak was revealed at $38.19^{\circ}$ which corresponded to predominant growth in the direction of (111) plane. The (200) plane can be assigned to the peak at $44.17^{\circ}$ and two observed peaks at $64.53^{\circ}$ and $77.43^{\circ}$ were attributed to the (220) and (311) respectively. All four peaks characterization for Ag system indicates that they are crystallized in cubic structure. It's so close to standard pattern [28]. The particle size was 
calculated by Scherer-Debye equation (Eq. 1) about $18.5 \mathrm{~nm}$.

$\mathrm{D}=\mathrm{K} \cdot \lambda / \beta \cdot \cos \theta$,

where all parameters are, respectively: $\mathrm{D}$, the size of the crystal, its unit is equal to $\lambda$ unit and is usually angstrom or $\mathrm{nm} ; \lambda$, the $\mathrm{X}$-ray wavelength; $\mathrm{K}=0.9$, the dimensionless shape factor, with a value close to unity; $\beta$, the full width at half maximum (FWHM); $\theta$, the peak position on the horizontal axis of diffraction pattern [29].

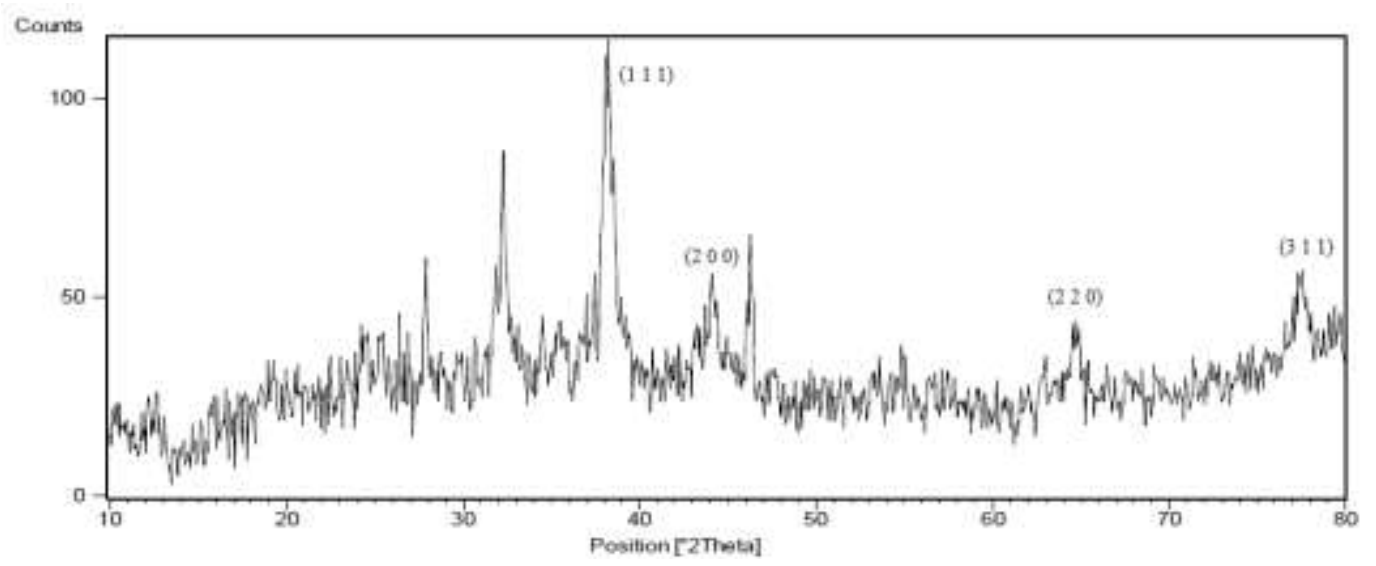

Figure 8. XRD pattern by powder of silver nanoparticles under optimum conditions

\section{FE-SEM and TEM analysis}

Microscopic techniques such as, Field Emission Scanning Electron Microscopy (FE-SEM), Transmission Electron Microscopy (TEM), are mainly used for morphological studies of nanoparticles. The FESEM image of the synthesized Ag NPs at the optimized condition is presented in Figure 9 and average range from $20-25 \mathrm{~nm}$. The TEM image of synthesized Ag NPs at the optimized condition is depicted in Figure 10 and was determined that, synthesized Ag NPs are spherical without any aggregates, the range of size was from 20-25 nm. As can be seen, the size of NPs by FE-SEM, TEM, and XRD methods is close together.

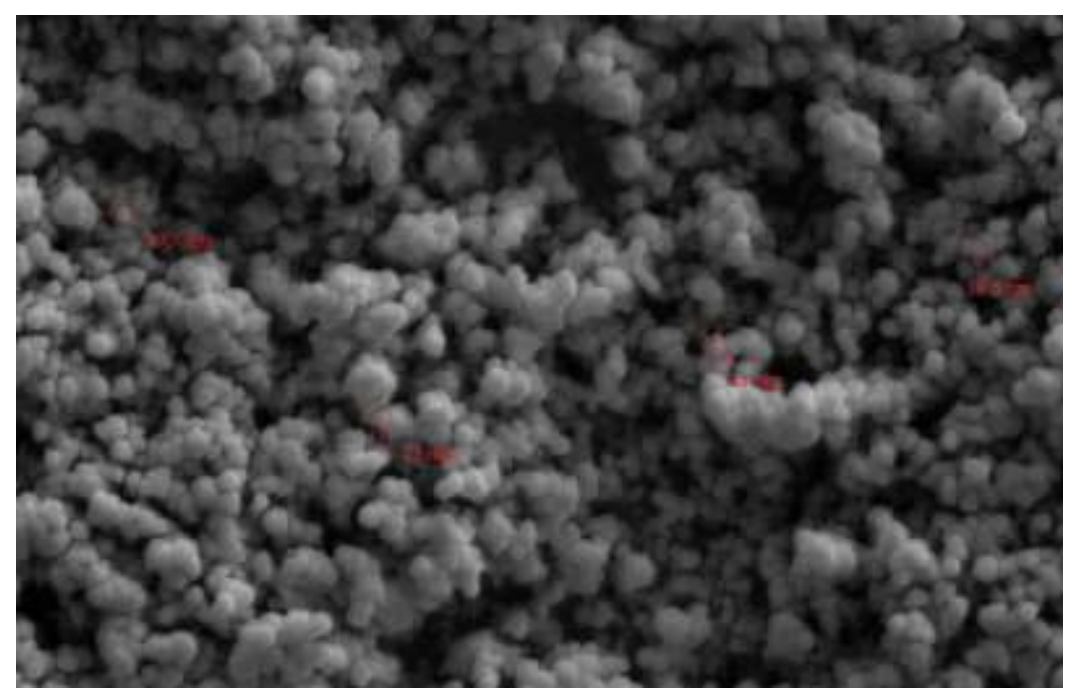

Figure 9. FESEM image of silver nanoparticles under optimum conditions 

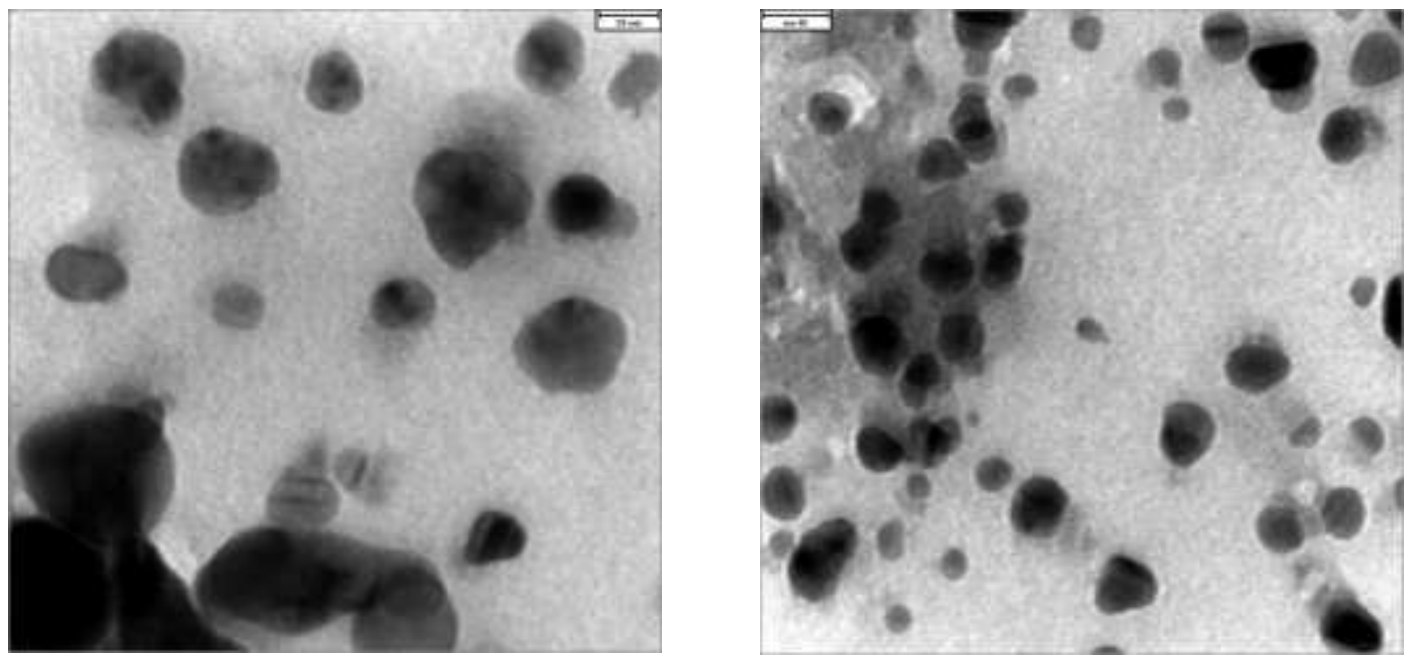

Figure 10. TEM images of silver nanoparticles under optimum conditions

A comparison of the with some extracts of the root of plants characterization results in present study is shown in Table 1.

Table 1. Comparison of characterization results of present study with some roots of the plants

\begin{tabular}{|c|c|c|c|c|}
\hline Conditions & $\begin{array}{c}\text { Absorbance } \\
\text { (nm) }\end{array}$ & Morphology & Characterization & Ref. \\
\hline $\begin{array}{l}\text { Morinda citrifalia } \\
\text { root extract }\end{array}$ & 413 & $30-55 \mathrm{~nm}$ & $\begin{array}{l}\text { UV, IR, TEM, XRD, } \\
\text { EDX, FESEM }\end{array}$ & {$[30]$} \\
\hline $\begin{array}{c}\text { Glyeyrrhiza globra } \\
\text { root extract }\end{array}$ & 440 & $\begin{array}{c}20 \mathrm{~nm} \\
\text { Spherical }\end{array}$ & UV, TEM, SED, EDX, IR & {$[31]$} \\
\hline $\begin{array}{l}\text { Zingiber officinale } \\
\text { root extract }\end{array}$ & 436 & $\begin{array}{l}10-20 \mathrm{~nm} \\
\text { Fcc }\end{array}$ & $\begin{array}{c}\text { UV, XRD, IR, SEM } \\
\text { EDX, TEM }\end{array}$ & {$[32]$} \\
\hline $\begin{array}{c}\text { Red ginseng root } \\
\text { extract }\end{array}$ & 410 & $\begin{array}{l}10-30 \mathrm{~nm} \\
\text { Spherical }\end{array}$ & $\begin{array}{c}\text { UV, FE-TEM, } \\
\text { EDX, XRD, DLS }\end{array}$ & {$[33]$} \\
\hline $\begin{array}{l}\text { Erythrina indica } \\
\text { lam root extract }\end{array}$ & 438 & $\begin{array}{l}20-118 \mathrm{~nm} \\
\text { Spherical }\end{array}$ & $\begin{array}{c}\text { UV, XRD, DLS, } \\
\text { EDX, IR, HR-TEM, }\end{array}$ & {$[25]$} \\
\hline $\begin{array}{c}\text { Panax giseng root } \\
\text { extract }\end{array}$ & 412 & $\begin{array}{l}10-30 \mathrm{~nm} \\
\text { Spherical }\end{array}$ & UV, TEM, EDX, XRD & {$[34]$} \\
\hline $\begin{array}{c}\text { Black carrot root } \\
\text { extract }\end{array}$ & 413 & $4.32-17.65 \mathrm{~nm}$ & UV, TEM & {$[35]$} \\
\hline Beet root & 439 & $\begin{array}{l}20-30 \mathrm{~nm} \\
\text { Spherical }\end{array}$ & $\begin{array}{l}\text { UV, XRD, IR, } \\
\text { FESEM, TEM }\end{array}$ & This study \\
\hline $\begin{array}{l}\text { Catalytic activity } \\
\text { NPs can be used } \\
\text { The catalytic a } \\
\text { strongly depende } \\
\text { and shape of }\end{array}$ & $\begin{array}{l}\text { an effective } \\
\text { ivity of } \\
\text { on composi } \\
\text { nanoparticle }\end{array}$ & $\begin{array}{l}\text { walyst. } \\
\text { was size } \\
\text { with }\end{array}$ & \multicolumn{2}{|c|}{$\begin{array}{l}\text { increasing surface to volume ratio, the } \\
\text { catalytic activity will increase [36]. The } \\
\text { silver NPs were used as a catalyst for } \\
\text { the reduction of } \mathrm{MB} \text { by } \mathrm{NaBH}_{4} \text { in this } \\
\text { study. Utilizing of } \mathrm{MB} \text {, a heterocyclic }\end{array}$} \\
\hline
\end{tabular}


aromatic dye, in the textile has increased in the last few years. Using large amount of MB leads to increase the undesirable toxicity in water. Toxicity in water is dangerous for human and plants [18]. The pseudo-first orders kinetics with respect to the concentration of $\mathrm{MB}$ was used to calculate the rate of constant $(\mathrm{k})$. Pseudo-first order can be described by (Eq. 2) [37, 38]:

$$
\mathrm{Ln} \frac{\boldsymbol{C o}}{\boldsymbol{c t}}=\mathrm{kt}
$$

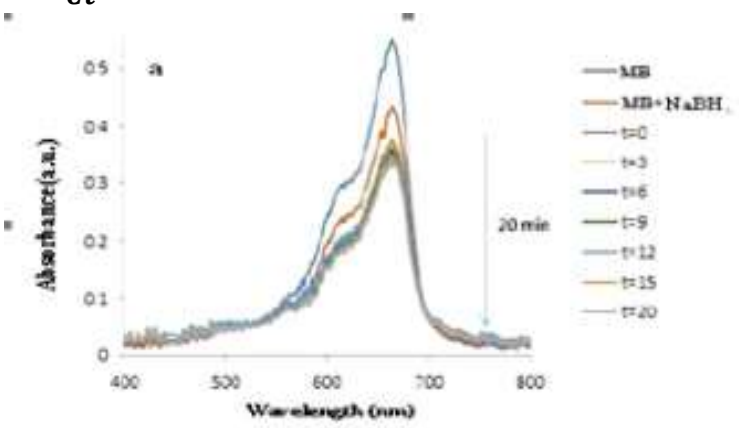

where $\mathrm{C}_{\mathrm{o}}$ is, the concentration of $\mathrm{MB}$ at $\mathrm{t}=0$ and $\mathrm{C}_{\mathrm{t}}$ is, the concentration of $\mathrm{MB}$ at time $\mathrm{t}$ and $\mathrm{k}$ is, the pseudo first orders rate of constant and $t$ is, reaction time. It is shown in Figure 11 that $\operatorname{Ln}\left(\mathrm{C}_{\mathrm{o}} / \mathrm{C}_{\mathrm{t}}\right)$ into $\mathrm{t}$ is acceptable linear, and slope of the linear graph gives the rate constant that was received that nearly is similar with other reported AgNPs and other conventional catalysts [39,40]. From (Eq. 2) $\mathrm{k}$ value was obtained $0.0194 / \mathrm{min}$.

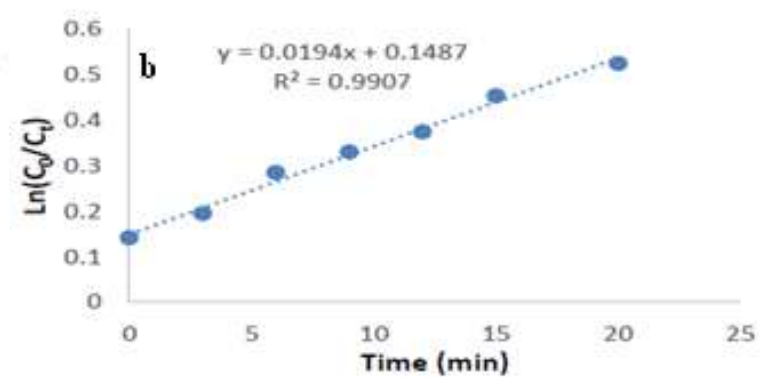

Figure 11. a) UV-Vis absorption of methylene blue solution in presence and absence of $\mathrm{NaBH}_{4}$ b) catalytic degradation of Methylene blue using Ag NPs

Antibacterial activity

The results of antimicrobial activity for the sample1 (silver NPs by Beetroot extract at $90{ }^{\circ} \mathrm{C}$ ) and sample 2 (silver NPs by Beetroot extract at room temperature $25{ }^{\circ} \mathrm{C}$ ) were measured by calculating the diameter of inhibition zones. The minimum concentration for inhibiting the growth of references bacteria was recognized and calculated.
In this sense, $30 \mu \mathrm{l}$ was the best minimum concentration for inhibiting the growth of pathogenic bacteria, because at concentration of $20 \mu \mathrm{l}$, the inhibition of growth was not seen clearly. Finally, the diameter of the inhibition zone was interpreted according to below instruction as the results were shown in Table 2 and Figure 12.
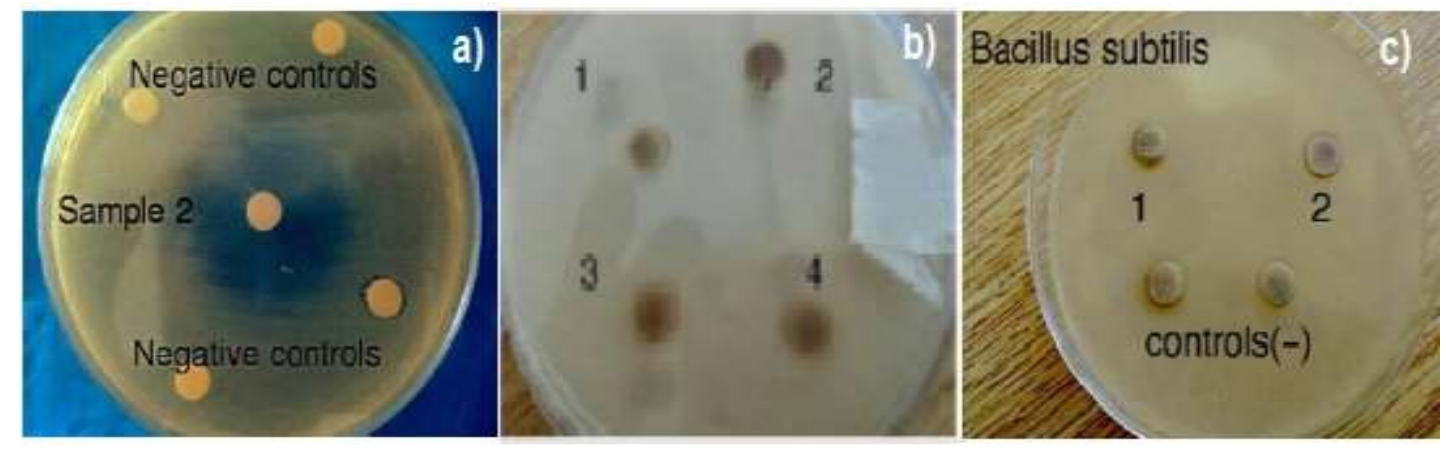

Figure 12. Antibacterial tests carried out on: a) Escherichia coli, b) Staphylococcus aureus, c) Bacillus subtilis 
Table 2. Results of antimicrobial test

\begin{tabular}{ccccc}
\hline $\begin{array}{c}\text { Samples } \\
\text { name }\end{array}$ & $\begin{array}{c}\text { Escherichia } \\
\text { coli }\end{array}$ & $\begin{array}{c}\text { Staphylococcus } \\
\text { aureus }\end{array}$ & $\begin{array}{c}\text { Bacillus } \\
\text { subtilis }\end{array}$ & $\begin{array}{c}\text { Salmonella typhy } \\
\text { murium }\end{array}$ \\
\hline 1 & ++ & - & - & ++ \\
2 & +++ & - & - & +++ \\
\hline (-) without inhibition zone, $0-3 \mathrm{~mm}(+), 3-5(++),>5 \mathrm{~mm}(+++)$ & &
\end{tabular}

During screening of sample1 and sample 2, we saw that Bacillus subtilis and Staphylococcus aureus completely grew but the growth of Salmonella and Escherichia coli were inhibited strongly Table 2, according to the results, gram negative bacteria were entirely sensitive to sample 1 and 2, In contrast, gram positive bacteria were resistant to sample 1 and 2 . It can be resulted by difference of the cell wall structure between gram positive and gram negative bacteria. Nowadays, strong resistance to different types of antimicrobial compounds among negative bacteria is considered as a serious problem in medical science. Producing and discovering natural products with amazing ability for inhibiting the growth of some dangerous bacteria (particularly negative bacteria) can be considered as a big revolution and great success in the field of medical science.

The UV-Vis spectral results refer to the formation of the Ag NPs using various parameters such as $\mathrm{pH}$, extract volume, salt concentration and time of reaction at room temperature.

The absorbance of solution increased significantly with a gradual increase of $\mathrm{pH}$ from 2 to 10 . It is related to the increase of silver NPs synthesis that; the highest value of absorbance is seen at $\mathrm{pH}=10$ in comparison to other $\mathrm{pH}$ values. As it is observed in Figure 3 at lower than $\mathrm{pH}=10$, Peaks shift to red wavelength that causes to increase the size of nanoparticles. On the contrary, at $\mathrm{pH}$ more than 10 , peaks shift to blue wavelength as results of decreasing the size of NPs [41].

In green synthesis of NPs by plants, plant acts as a reductant of metal ions and stabilizer of nanoparticles [42]. According to Figure 4 with increasing the amount of extract from 0.1 to $2 \mathrm{~mL}$, the value of NPs absorbance increases sharply and more NPs are produced [43].

Figure 5 shows that as the concentration of $\mathrm{AgNO}_{3}$ was increased from $1 \mathrm{mM}$ to $5 \mathrm{mM}$, the absorption peak increased as well. More ions are reduced by increasing the amount of silver ions, subsequently, more nanoparticles are produced. With adding more $\mathrm{AgNO}_{3}$, NPs are joined to each other and NPs become bigger.

Figure 6 shows that most of the NPs are formed at 40 and 60 minutes, also it is important that, the best time of optimum depends on peak symmetry and small size of NPs. The best results were obtained at $\mathrm{pH}=10$, extract volume $2 \mathrm{~mL}$, salt concentration $3 \mathrm{mM}$ and reaction time $=60 \mathrm{~min}$. Pseudo first order model reaction with rate constant $\left(\mathrm{k}=0.0194 \mathrm{~min}^{-1}\right)$ corresponds to the experiment data of removal of Methylene Blue was observed. Antibacterial results show, gram negative bacteria are so sensitive to synthesized silver NPs.

\section{Conclusion}

We found out a simple green protocol for synthesizing and surveying antibacterial properties and catalytic activity of the silver NPs from the Beetroot extract. Ag NPs were 
synthesized using Beetroot extract at optimum conditions. The NPs were characterized by UV-Vis, FTIR, XRD, FESEM and TEM techniques. The UVVis analysis determined the Surface Plasmon Resonance of the AgNPs. The FT-IR measurements were applied to identify the potential of functional NPs that can be used as beneficial and practical catalysts. The FE-SEM, TEM, and XRD techniques confirmed the formation of cubic and crystalline structure. NPs have improved catalytic activity, because larger surface area and smaller size are considered as important features in nanoparticles. The catalyst is eco-friendly and stable, because, it produces negligible waste without significant loss of activity and with nearly complete conversion. However, the mechanisms behind the activities of NPs need to be precisely studied in detail. The functional aspect of the silver NPs in terms of their surface crystallization, stability and size distribution was significantly acquired. On the whole, the synthesized silver NPs bring a valuable opportunity for controlling and inhibiting the growth of some pathogenic and dangerous bacteria, as well as, good catalytic activity should be considered as its other advantage.

\section{Acknowledgements}

The authors are grateful of the Islamic Azad University of Arak for financial supports.

\section{References}

[1] K.S. Kavitha, S.B. Rakshith, D. Rakshith, HU. Kavitha, H.C. Yashwantha B.P. Harini, S. Satish, Int. Res. J. Biol. Sci., 2013, 2, 66-76.

[2] H.S. Mansur, F. Grieser, M.S. Marychurch, S. Biggs, R.S. Urquhart, D.N. Furlong, J. Chem. Soc. Faraday. Trans., 1995, 91, 665-672.
[3] M. Kamali, S.S.K.Ghorashi, M.A. Asadollahi, Iran. J. Chem. Chem. Eng., 2012, 31, 21-28.

[4] A. Ahmad, P. Mukherjee, P. Senapati, D. Mandal, M.I. Khan, R. Kumar, M. Sastry, Colloids Surf. B 2003, 28, 313-318.

[5] (a) A. Bharde, A. Kulkarni, M. Rao, A. Prabhune, M. Sastry, J. Nanosci. Nanotechnol., 2007, 7, 4369-4377; (b) S. Sajjadifar, Chemical Methodologies, 2017, 1, 1-11; (c) S. Rezayati, S. Sajjadifar, Journal of Sciences, Islamic Republic of Iran, 2014, 25, 329-337; (d) H. Veisi, D. Kordestani, S. Sajjadifar, M. Hamelian, Iran. Chem. Commun., 2014, 2, 27-33.

[6] T. Douglas, E. Strable, D. Willits, A. Aitouchen, M. Libera, M. Young, Adv. Mater. 2002, 14, 415-418.

[7] (a) S. Gurunathan, K.J. Lee, K. Kalishwaralal, S. Sheikpranbabu, R. Vaidyanathan, S.H. Eom, Biomaterials., 2009; 30, 6341-6350; (b) H. Veisi, A. Sedrpoushan, P. Mohammadi, A.R. Faraji, S. Sajjadifar, RSC Advances, 2014, 4, 25898-25903; (c) S. Sajjadifar, M.A. Zolfigol, G. Chehardoli, S. Miri, International Journal of ChemTech Research, 2013, 5, 422-429.

[8] I. Sheikhshoaie, S. Davary, S. Ramezanpour, Chem. Methodol., 2018, 2, 47-55.

[9] (a) B.M. Ganesh, P. Gunasekaran, Colloids Surf. B, 2009, 74, 191-195; (b) E. Rezaee Nezhad, S. Sajjadifar, Z. Abbasi, S. Rezayati, Journal of Sciences, Islamic Republic of Iran, 2014, 25, 127-134.

[10] (a) J.L. Gardea-Torresdey, J.G. Parsons, E. Gomez, J. Peralta-Videa, H.E. Troiani, P. Santiago, M.J. Yacaman, Nano Lett., 2002, 2, 397-401; (b) E. Rezaee Nezhad, F. Heidarizadeh, S. Sajjadifar, Z. Abbasi, Journal of Petroleum Engineering, 2013, 2013, http://dx.doi.org/10.1155/2013/203036;

(c) S. Sajjadifar, International Journal 
of ChemTech Research, 2013, 5, 385389.

[11] J.L. Gardea-Torresday, E. Gomez, J. Peralta-videa, J.G. parsons, H.E. Troiani, M. Jose-Yacaman, Langmuir 2003, 19, 1357-1361.

[12] N.S. Powar, V.J. Patel, P.K. Pagare, R.S. Pandav, Chem. Methodol., 2019, 3, 457-480.

[13] F. Mohammadi, M. Yousefi, R. Ghahremanzadeh, Adv. J. Chem. A, 2019, DOI:

10.33945/SAMI/AJCA.2019.4.2.

[14] T. AB Matin, N. Ghasemi, K. Ghodrati, M. Ramezani, Iran. Chem. Commun. 2019, DOI: 10.30473/icc.2019.45837.1539.

[15] J. Yong Song, B. Soo Kim, Bioproc. Biosystems. Eng., 2009, 32, 79-84.

[16] (a) N. Ahmad, S. Sharma, Green Sustainable Chem., 2012, 2, 141-147; (b) M.A. Zolfigol, H. Vahedi, A. Massoudi, S. Sajjadifar, O. Louie, Clinical Biochemistry, 2011, 13, S219; (c) S. Sajjadifar, H. Vahedi, A. Massoudi, O. Louie, Molecules, 2010, 15, 2491-2498; (d) S. Sajjadifar, Z. Arzehgar, A. Ghayuri, Journal of the Chinese Chemical Society, 2018, 65, 205-211.

[17] A. Zainalabidine, Y. Rosiyah, S. Shamaladevi, Adv. Mater. Sci. Eng., 2016,

http://dx.doi.org/10.1155/2016/4102196 [18] N.N. Bonnia, M.S. Kamaruddin, M.H. Nawawi, S. Ratimd, H.N. Azlina, E.S. Ali, Procedia Chem., 2016, 19, 594-602.

[19] J. Saha, A. Begum, A. Mukherjee, S.A. Kumar Sustain. Environment. Res., 2017, 27, 245-250.

[20] (a) B. Ajitha, Y. Ashok Kumar Reddy, H.J. Jeon, CW. Ahn, $A d v$. Powder Technol., 2017, 29, 86-93; (b) S. Sajjadifar, O. Louie, Journal of chemistry, 2013, 2013, http://dx.doi.org/10.1155/2013/674946; (c) S. Sajjadifar, G. Mansouri, S. Miraninezhad, Asian J. Nanosci. Mater., 2018, 1, 11-1; (d) S. Sajjadifar, S. Rezayati, International Journal of ChemTech Research, 2013, 5, 19641968.

[21] A.G. R Jose, T. Abirami, V. Kavitha, R. Sellakilli, J. Karthikeyan, J. Pharmacogn Phytochem., 2018, 7, 24532457.

[22] J.H. Von Elbe, I. Young maing, C.H. Amundson, J. Food Sci., 2006, 39, 334-337.

[23] F. Delgado-Vargas, A.R. Jiménez, O. Paredes- López, Crit. Rev. Food Sci. Nutr. 2000, 40, 173-189.

[24] S.L. Smitha, P. Daizy, K.G. Gopchandran, Spectrochim. Acta. A 2009, 74, 735-739.

[25] M.M.H. Khalil, E.H. Ismail, K.Z. El-Baghdady, D. Mohamed, Arab. J. Chem., 2014, 7, 1131-1139.

[26] V. Armendariz, I. Herrera, J.L. Gardea-Torresdey, J. Peralta-videa, $J$. Nanoparticle Res., 2004, 6, 377-382.

[27] S.P. Dubey, M. Lahtinen, M. Sillanpaa, Process Biochem., 2010, 45, 1065-1071.

[28] R. Heydari, M. Rashidpour, Int. J. Breast Cancer., 2015, 2015, http://dx.doi.org/10.1155/2015/846743.

[29] F. Malek Mohammadi, N. Ghasemi, J. Nanostructure Chem. 2018, 8, 93-102.

[30] T.Y. Suman, S.R. Rajasree, R. Ramkumar, C. Rajthilak, Spectrochim. Acta A 2014, 118, 11-16.

[31] S. Dinesh, S. Karthikeyan, P. Arumugam, Arch. Appl. Sci. Res., 2012, 4, 178-187.

[32] P. Velmurugan, K. Anbalagan, M. Manosathyadevan, Bioprocess. Biosyst. Eng., 2014, 37, 1935-1943.

[33] P. Singh, Y.J. Kim, C. Wang, R. Mathiyalagan, M. El-Agamy Farh, D.C. Yang, Artif. Cells Nanomed. Biotechnol., 2016, 44, 811-816. 
[34] P. Singh, Y.J. Kim, C. Wang, R. Mathiyalagan, D.C. Yang, Artif. Cells Nanomed. Biotechnol., 2016, 44, 11501157.

[35] A. Abubakar, I.B. Salisu, S Chahal, Int. J. Cur. Res. Rev., 2014, 6, 5-8.

[36] M.C. Daniel, D. Astruc, Chem. Rev., 2004, 104, 293-346.

[37] B. Ajitha, Y. Ashok Kumar Reddy, H.J. Jeon, C.W. Ahn, Catal. Sci. Technol., 2016, 6, 8286-8299.

[38] L. Ai, H. Yu, J. Jiang, J. Mater. Chem., 2012, 22, 23447-23453.
[39] V.A. Kumar, Y. Nakajima, T. Uchida, T. Hanajari, T. Maekawa, Mater. Lett., 2016, 176, 169-172.

[40] A. Khorshidi, N. Mardazad, Res. Chem. Intermed., 2016, 42, 7551-7558.

[41] R. Sre, M. Reka, R. Poovazhagi, K. Murugesan, Spectrochim. Acta A 2014, 135, 1137-1144.

[42] J. Kasthuri, N, Rajendiran, Colloids Surf. B 2009, 73, 387-393.

[43] M. Kasithevar, M. Saravanan, P. Prakash, H. Kumar, M. Ovais, H. Barabadi, Z.H. Shinwari, J. Interdiscip. Nanomed., 2017, 2, 131-141.

How to cite this manuscript: Sima Mehdizadeh, Nahid Ghasemi, Majid Ramezani. "The synthesis of silver nanoparticles using Beetroot extract and its antibacterial and catalytic activity”. Eurasian Chemical Communications, 2019, 545-558. 